\title{
Ergonomic Evaluation and Redesign Manual Brick Work Station in The Village of Sail
}

\author{
Merry Siska $^{1}$, Eki Saputra ${ }^{2}$ and Reski Mai Candra ${ }^{3}$ \\ ${ }^{1}$ Industrial Engineering Department, Universitas Islam Negeri Sultan Syarif Kasim Riau, HR Soebrantas Street 155, Pekanbaru, \\ Indonesia \\ ${ }^{2}$ Information System Department Universitas Islam Negeri Sultan Syarif Kasim Riau, HR Soebrantas Street 155, Pekanbaru, Indonesia \\ ${ }^{3}$ Informatic Engineering Department, Universitas Islam Negeri Sultan Syarif Kasim Riau Riau, HR Soebrantas Street 155, Pekanbaru, \\ Indonesia
}

\begin{abstract}
Working posture or work attitude is the working position is naturally formed by the body of workers due to the facilities used to interact with or work habits. Unsuitable working attitude can cause physical complaints such as pain in the muscles (Musculoskeletal Complain). Brick-making factories were encountered in the Village of Sail. This research is a field where once obtained the data needed and then do the processing of the data from the mapping process operations, risk evaluation work experienced by workers by using OCRA Checklist, calculate the value OCRA index, focus group discussions problems faced by workers, design repair work method proposed, calculates the data anthropometry workers, prototyping proposed workstation moulding bricks and evaluate the results of the optimization workstation moulding bricks. After all, factors rated the results of activities scored bricks have totalled a score of 23.19 for the body of the left and amounted to 25.13 to the right part of the body. This value is high because the number of ATA and RTA are very much different. If the number of recommended actions (RTA) is smaller than the number of actual action (ATA) then there is a risk assessment of musculoskeletal disorders.
\end{abstract}

\section{Introduction}

The number of companies in Indonesia currently lead the increasingly fierce competition, one of which is SMEs. The embryo of SMEs in Indonesia stems from activity home industry in the community, group of farmers, craftsmen, farmers groups, associations and others. Starting from people who want to become economically independent, with limited capital capability smaller groups can grow and develop into a Micro, Small and Medium Enterprises (SMEs) [1]. SME sector has a major contribution in employment, which absorbs more than $99.45 \%$ of the workforce and contribution to GDP is around $30 \%$ [2].

Until December 2012, Indonesia has 69,249 villages spread evenly across the archipelago. However, the growth of villages throughout Indonesia is not as evenly village existence. According to the Chairman of the Association of Disadvantaged District, Jayabaya Mulyadi, said as many as 32 thousand villages in Indonesia in the category of left behind. Indonesia Central Government continues to alleviate to catch up. $\dagger$ One way to improve the life and economy of the village is to promote small and medium enterprises (SMEs) in the village. In Indonesia, SMEs are the backbone of the Indonesian economy. The number of SMEs in Indonesia until 2011 to reach around 52 million. $\$$ It accounts for $60 \%$ of GDP and holds $97 \%$ of the labor force. Although the quantity is very large and laborintensive, the share of national income is still about $57 \%$. That figure is far less than its share of the conglomerates that are small but very dominating Indonesian economy [3].

MSDs are part of the occupational health problems in waste industries in developing countries [4-5]. The posture of a human body at work is influenced by several factors, including workstation layout (height of the workplace, the orientation of tools and work objects), hand tools design, work methods, and work habits, visual control and force exertion requirements and characteristics of the workers [5-6]. Poor and un-natural working posture have been associated with the onset of fatigue, body discomfort, pains and musculoskeletal disorders $[5,7]$.

Work postures or work attitude is the working position is naturally formed by the body of workers due to the facilities used to interact with or work habits. Unsuitable working attitude can cause physical complaints such as pain in the muscles (Musculoskeletal Complain). Musculoskeletal Disorders (MSDs) is a disorder of skeletal muscle sections were perceived by 
someone from mild impairment to severe impairment. When someone receives a static load repeatedly and for a long time, will be able to cause a disruption in the form of damage to the joints, ligaments and tendons [8]. Thus we need to design a working posture and ergonomic workstations to provide comfort work to prevent complaints of occupational diseases and to improve productivity.

Brick-making factories were encountered in the Village of Sail. The Village of Sail in Pekanbaru city is the outer area of the municipal district of Pekanbaru. This area can be said to be still lagging behind areas - other areas. However, this area can also be said of small and medium industrial zones.

The worker will be working on two types of work or tasks to perform brick moulding process. The first task is to prepare the clay until ready to mould and moulding tasks into two is clay to be ready for drying wet bricks. The first task requires more force because the operators prepare the clay of the form of chunks enough weight to compact for easy moulding. While on assignment to two carriers that require precision moulded bricks have good results and solid. Because of his work process is still manual labour the rate specified by the operator. Figure 1-2 illustrates how operators work in the task of preparing the clay

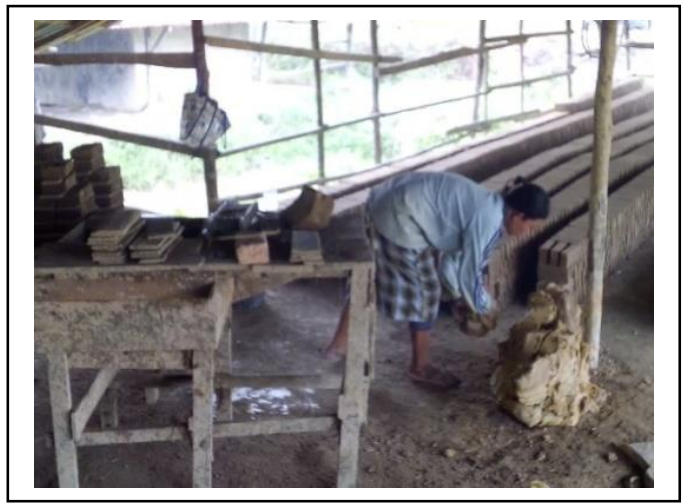

Figure 1. Worker Bend Her Back to Get Clay on The Floor

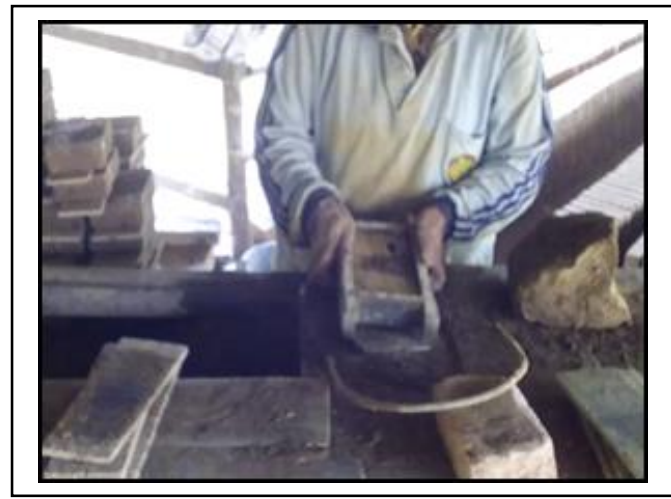

Figure 2. Worker Mould The Clay Using Traditional Tools

Questionnaire PLIBEL is early screening tool in the form of a simple check sheet aimed at highlighting the risks of the musculoskeletal workplace. This method was chosen because this questionnaire targeting risk factors through a common question, simple, and can be used for any type of work [9]. The results of a questionnaire PLIBEL identification, risk exposure in the form of a percentage of musculoskeletal disorders in various areas of the body. These results will be used to support verbal interviews and can be seen in Table 1 .

Table 1. The Results of PLIBEL's Questionnaire

\begin{tabular}{|c|c|c|c|c|c|}
\hline \multirow{2}{*}{ Worker } & \multicolumn{5}{|c|}{ Musculoskeletal Risk Factor } \\
\cline { 2 - 6 } & $\begin{array}{c}\text { Neck, } \\
\text { Shoulder } \\
\text { s, Back }\end{array}$ & $\begin{array}{c}\text { Elbows, } \\
\text { forear, } \\
\text { hands }\end{array}$ & Feet & $\begin{array}{c}\text { Knees } \\
\text { and hips }\end{array}$ & $\begin{array}{c}\text { lower } \\
\text { back }\end{array}$ \\
\hline 1 & $34.60 \%$ & $27.20 \%$ & $16.20 \%$ & $16 \%$ & $14.20 \%$ \\
\hline 2 & $50 \%$ & $54.50 \%$ & $19.50 \%$ & $13 \%$ & $28.50 \%$ \\
\hline 3 & $30.70 \%$ & $27.20 \%$ & $1870 \%$ & $12.50 \%$ & $14.20 \%$ \\
\hline 4 & $38.40 \%$ & $36.30 \%$ & $16.60 \%$ & $14 \%$ & $14.20 \%$ \\
\hline Average & $\mathbf{3 8 . 4 2 \%}$ & $\mathbf{3 6 . 3 \%}$ & $\mathbf{1 7 . 7 5 \%}$ & $\mathbf{1 3 . 9 2 \%}$ & $\mathbf{1 7 . 7 7 \%}$ \\
\hline
\end{tabular}

Table 1. shows that the exposed body part most significant musculoskeletal disorders are the upper body / upper limb (neck, shoulders, upper back, elbows, hands, and arms). This is because of the manual process performed by the operator greater involvement of the upper body, especially the hands. The magnitude of this percentage is also caused by the operator answers to the questions concerning the working posture, tools, situations and work environments, as well as repetitive activities undertook more leads to the risk of exposure to the upper body musculoskeletal disorders.

\section{Methods}

One method for analyzing musculoskeletal disorders is OCRA method where this method can provide an assessment of the relative risks of musculoskeletal disorders are the number of risk factors are more and more detail than other methods. OCRA methods used to analyze the impact of workers to tasks that displays various risk factors work injury, especially in the upper body (repetition of work, strength, posture and movement that is not good, the lack of recovery period, and so forth). OCRA Index is a method that can generally be used to design or redesign both workstations and work there. While the OCRA checklist is the simplest way to apply is generally recommended as the initial examination workstation or work that displays repetitive activity[10].

The basic concept in OCRA is technical action, defined as a complex movement to complete a work task, which involves one or more joints of the upper limb. The OCRA index is calculated as a ratio of the foreseeable frequency (FF) of technical actions per minute and the corresponding number of recommended actions called the reference frequency (RF) of technical actions per minute. $\mathrm{RF}$ is the product of seven multipliers: posture multiplier (PoM), force multiplier (FoM), repetitiveness multiplier $(\mathrm{ReM})$, recovery multiplier $(\mathrm{RcM})$, duration multiplier (DuM), additional factors multiplier (AdM) and a constant of frequency (30 actions per minute) of technical actions per minute (CF) [11].

This method is used to direct and facilitate the troubleshooting process and analyze the results of processing through good research management so that the research conducted can be more qualified. Each stage in 
the research methodology is an important part that must be done properly and carefully.

The design tools in redesigning brick moulding station are designed based on anthropometric data of workers. In connection with this, the need for multiple data anthropometric measure that will be used to redesign. The use of anthropometric data associated with the user and the selection of subjects corresponding data

\section{Results and Discussion}

\subsection{Comparison of Energy Consumption}

Calculation workers heart rate data during the initial work is done to determine how much of the energy consumption of the job. Heart rate data moulding worker bricks obtained from the processed data collection to determine the energy consumption on the job, in the moments before and after the redesign. The comparison of the energy consumption of moulding workers brick before and after the redesign can be seen in Table 2 .

Table 2. Comparison of Average Physiology Data

\begin{tabular}{|c|l|c|c|c|c|}
\hline \multirow{2}{*}{ No. } & Description & \multicolumn{2}{|c|}{ Before Redesign } & \multicolumn{2}{c|}{ After Redesign } \\
\cline { 3 - 6 } & $\begin{array}{c}\text { Before } \\
\text { Working }\end{array}$ & $\begin{array}{c}\text { After } \\
\text { Working }\end{array}$ & $\begin{array}{c}\text { Before } \\
\text { Working }\end{array}$ & $\begin{array}{c}\text { After } \\
\text { Working }\end{array}$ \\
\hline 1 & $\begin{array}{l}\text { Heartbeat } \\
\text { (Pulse/min) }\end{array}$ & 74.62 & 96.92 & 73.94 & 86376 \\
\hline 3 & $\begin{array}{l}\text { Oxygen } \\
\text { Consumption } \\
\text { Liters/min }\end{array}$ & 0.492 & 0.938 & 0.478 & 0.727 \\
\hline & $\begin{array}{l}\text { Energy } \\
\text { consumption } \\
\text { kcal/min) }\end{array}$ & 2.364 & 4.504 & 2.298 & 3.492 \\
\hline
\end{tabular}

Table 2 shows the average energy consumption required by a moulding worker bricks before the design is equal to 2,364 kcal before work and after work amounted to $4,504 \mathrm{kcal}$. This means that the energy expended in the time before work amounted to 2,364 Kcal and the energy expended after work amounted to 4,504 Kcal workload that qualifies as"light" seen from heart rate, oxygen consumption, and energy consumption. While the condition of the drafting of the average energy consumption is issued upon the prior work amounted to 2,298 Kcal and after work amounting to 3,492 Kcal. This means that the energy expended before doing the work amounted to 2,298 Kcal and the energy expended after doing the work amounted to 3,492 Kcal workload that qualifies as"light" seen from heart rate, oxygen consumption, and energy consumption. Where workers can save energy as much as $1,012 \mathrm{Kcal} /$ minute after using the tools and moulding facilities bricks after the redesign.

\subsection{Comparison of Working Time}

Data time existing work processes before and after redesign will be processed to determine the standard time working process. Test uniformity and adequacy of the data of standard time moulding the bricks before the redesign was observed from one worker for 30 times observation is at the upper control limit (UCL) and lower control limits (LCL) and test the adequacy of that has been done stating the samples taken have enough Because $\mathrm{N}^{\prime}<\mathrm{N}$, namely $5.95<900$, then the data moulding time said enough bricks. Uniformity test data when moulding bricks after redesigning observed from one worker for 30 times observation is at the upper control limit (UCL) and lower control limits (LCL) and test the adequacy of the data that has been made stating the samples taken have been quite as $\mathrm{N}^{\prime}<\mathrm{N}$ is $7.42<900$, then the data moulding time said enough bricks.

After the test data uniformity and adequacy of the data has been completed, it can be processed further to determine the time of moulding raw brick, both before and after the redesign. [The comparison of the time standard brick moulding before and after the redesign can be seen in Table 3 .

Table 3. Comparison of Average Time Moulding Bricks

\begin{tabular}{|c|c|c|c|c|}
\hline Description & $\begin{array}{c}\text { Before } \\
\text { Redesign }\end{array}$ & $\begin{array}{c}\text { Allowan } \\
\text { ce }\end{array}$ & $\begin{array}{c}\text { After } \\
\text { Redesign }\end{array}$ & $\begin{array}{c}\text { Allowan } \\
\text { ce }\end{array}$ \\
\hline Cycle Time & $\begin{array}{c}21.97 \\
\text { seconds }\end{array}$ & & $\begin{array}{c}16.41 \\
\text { seconds }\end{array}$ & \\
\cline { 1 - 1 } Normal time & $\begin{array}{c}24.13 \\
\text { seconds }\end{array}$ & \multirow{2}{*}{$23.5 \%$} & $\begin{array}{c}18.93 \\
\text { seconds }\end{array}$ & \multirow{2}{*}{$20.5 \%$} \\
\cline { 1 - 2 } $\begin{array}{c}\text { Standard } \\
\text { Time }\end{array}$ & $\begin{array}{c}29.8 \\
\text { seconds }\end{array}$ & $\begin{array}{c}22.81 \\
\text { seconds }\end{array}$ & \\
\hline
\end{tabular}

\subsection{Productivity Comparison}

In determining the productivity of the condition before and after the design can be determined by output standard produced and labour time used by workers.

1. Before Redesign

In the first working day for 420 minutes, the time standard brick moulding process time before redesigning amounted to 29.8 seconds and output the default is 845 units of bricks /day.

2. After Redesign

Raw Time of brick moulding manufacturing process after the redesign amounted to 22.81 seconds and output the default is 1105 units of bricks /day.

Based on the data processing before the redesign, the standard time in a brick moulding process requires 29.8 seconds. Meanwhile, after the redesign, the standard time in the moulding becomes shorter brick is 22.81 seconds. Reduction of the standard time before and after the redesign affect the number of output standard produced is of 845 units of bricks/day produced before redesigning be 1105 units of bricks/day after the redesign. Labour productivity increased from 845 units of bricks/day before redesigning be 1105 units of bricks/day after a redesign or an increase in productivity by $30.76 \%$.

The redesign results brick moulding workstations based participatory ergonomics can be seen in Figure 3-5. 


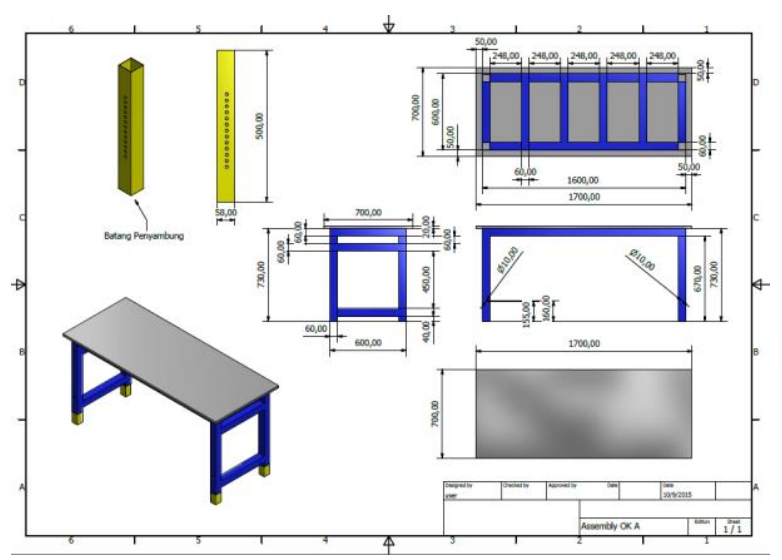

Figure 3. Redesign Table for Moulding Bricks

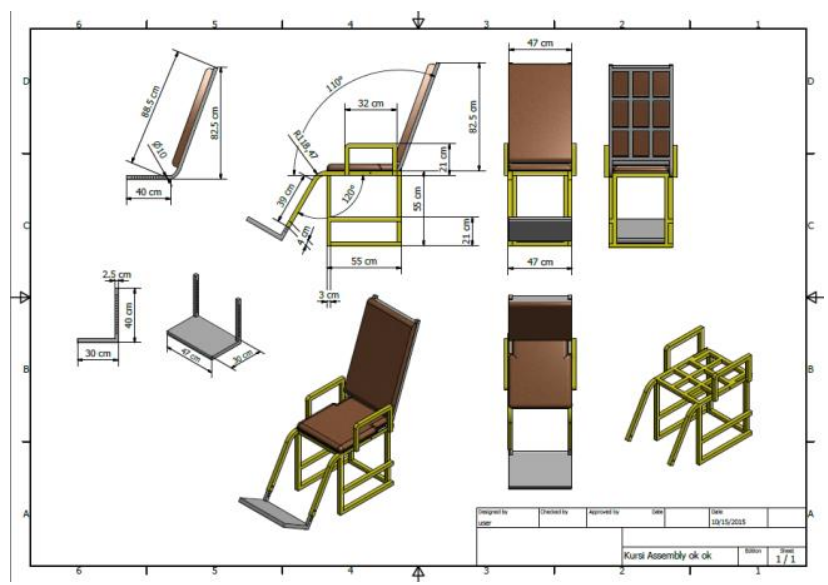

Figure 4. Redesign Rest Seat while Idle

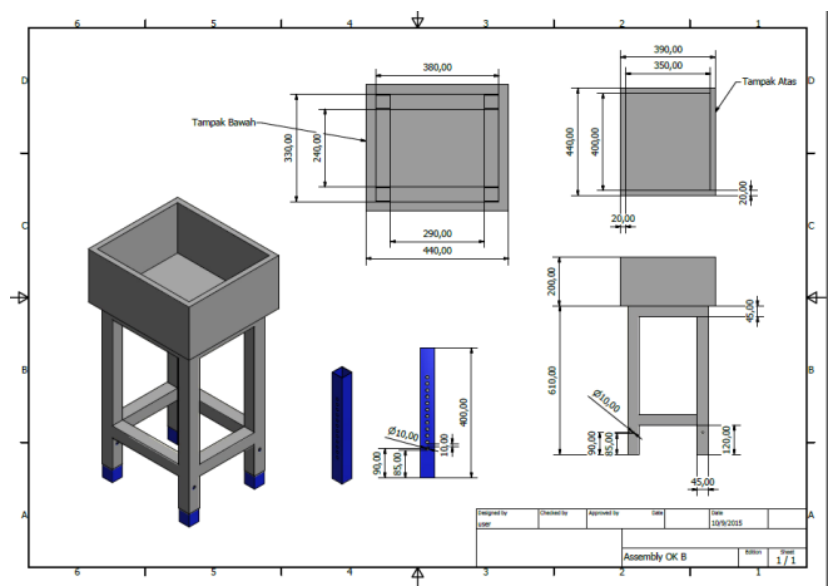

Figure 5. Redesign of The Powder Box

Recapitulation of musculoskeletal disorders risk classification criteria OCRA Checklist is shown in Table 4. Redesign table, seat and powder box in moulding bricks in real condition can be shown in Figure 6-8.

Table 4. Summary of musculoskeletal disorders risk classification based on criteria OCRA checklist bricks

\begin{tabular}{|l|c|c|c|c|}
\hline $\begin{array}{c}\text { Event } \\
\text { type }\end{array}$ & Body Part & $\begin{array}{c}\text { OCRA } \\
\text { Checklist }\end{array}$ & Level & $\begin{array}{c}\text { Risk } \\
\text { Classification }\end{array}$ \\
\hline $\begin{array}{l}\text { Moulding } \\
\text { Brick }\end{array}$ & Left & 81.39 & Purple & High Risk \\
\cline { 2 - 5 } & Right & 178.29 & Purple & High Risk \\
\hline
\end{tabular}

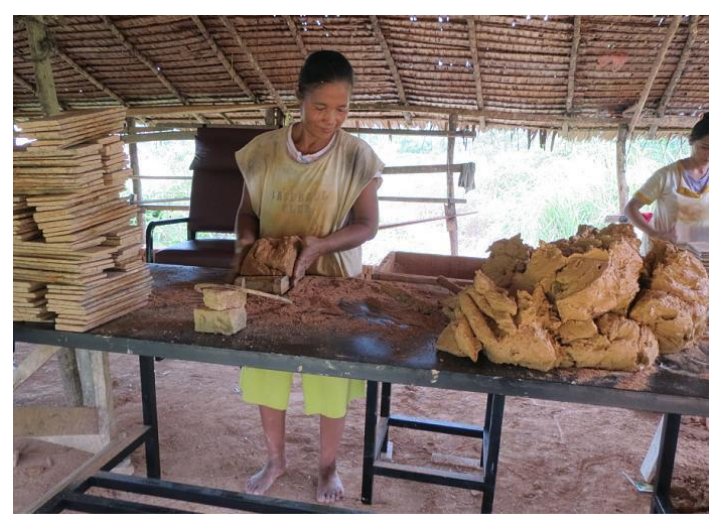

Figure 6. Redesign table for moulding bricks in real condition

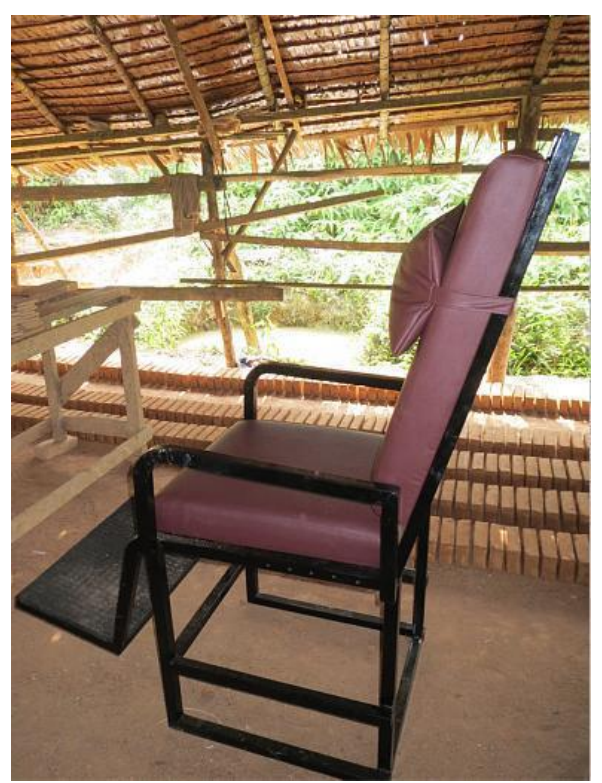

Figure 7. Redesign rest seat while break time in real condition

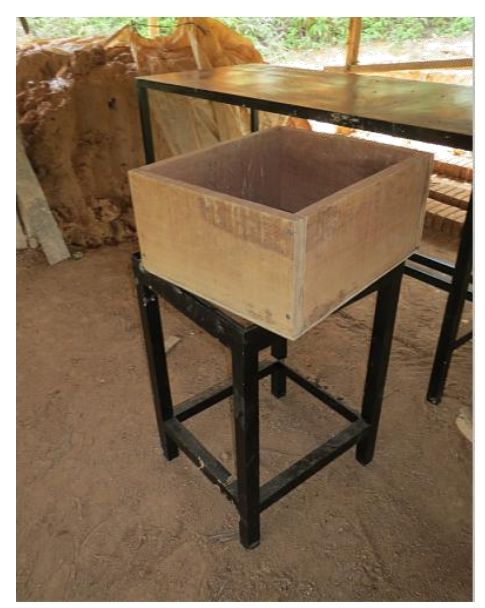

Figure 8. Redesign of the powder box

\section{Conclusion}

The results of printing bricks have a score of 23.19 for left body and number 25.13 for the right body. This value is high because the number of ATA and RTA is very different. The high rate of repetition of each activity that occurs in brick printing multiplied by the number of 
production targets per day makes the number of actual technical actions that occur on the field very high.

The design table for printing bricks can also be set in height so that workers who have a waist height stand can use it according to the size of the waist height. It is intended that workers work with a comfortable work posture and can optimize movement in their work.

Redesigned wood powder tables can also be set in height so that workers who have different standing height variable can use it according to the size of their waist height. It is intended that workers work with a comfortable work posture and can optimize movement in their work. The percentile is $5^{\text {th }}$ chosen so that the resting chair designed can be used by all workers who have different sizes. This is so that workers can use chairs to rest comfortably while fatigue at work.

\section{References}

1. N. W. Setyanto, R. Himawan, Zefry, E. Y. Arifianto, R. M. S. Puteri, and N. Kurnia, Perancangan Alat Pengering Mie Ramah Lingkungan, Jurnal Rekayasa Mesin, 3, 411-420 (2012)

2. Y.R. Suci, Perkembangan UMKM (Usaha mikro kecil dan menengah) di Indonesia. Cano Ekonomos, 6, 51-58 (2017)

3. Z. Hutabarat and M. Pandin, Absorptive Capacity of Business Incubator for SME's Rural Community Located in Indonesia's Village. Procedia-Social and Behavioral Sciences, 115, 373-377 (2014)
4. E. Valero, A. Sivanathan, F. Bosché, and M. AbdelWahab, Musculoskeletal Disorders in Construction: A Review and a Novel System for Activity Tracking with Body Area Network. Applied Ergonomics, 54, 120-130 (2016)

5. A. I. Musa, A. A. Yussouff, N. A. Raji, T.S. Ogedengbe, and R. O. Saheed, Ergonomics Investigation of Musculoskeletal Disorder Among the Workforce of Waste Management Industry in Nigeria. TRANSACTIONS of the VŠB-Technical University of Ostrava, Safety Engineering Series, 12(2), 61-65 (2017)

6. D. B. Chaffin, G.B. Anderson, and D. J. Martin, Occupational Biomechanics, 3rd ed John Wiley and Sons publisher, New York, 65-13 (1992)

7. O. Karhu, E. Kansi, and I. Akuorinka, Correcting Working Postures in Industry: A Practical Method for Analysis. Applied Ergonomics, 8(4): 199-201. (1997)

8. HSE (Health and Safety Executive) Musculoskeletal Disorders in Great Britain ( 2014)

9. N. A. Stanton, Human factors and ergonomics methods. In Handbook of human factors and ergonomics methods, CRC Press, 27-38 (2004)

10. J. Malchaire, G. Gauthy, A. Piette, and F. Strambi, $A$ Classification of Methods for Assessing and/or Preventing the Risks of Musculoskeletal Disorders. ETUI (2011).

11. D. Roman-Liu, A. Groborz, and T. Tokarski, Comparison of Risk Assessment Procedures Used in OCRA and ULRA Methods. Ergonomics, 56(10), 1584-1598(2013) 